Ann. Biol. anim. Bioch. Biophys., I970, 10 (2), 317-32i2.

NOTE

\title{
UTILISATION DES ACIDES AMINÉS DU TOURNESOL POUR LA CROISSANCE DU RAT : INFLUENCE DU TAUX PROTÉIQUE DE LA RATION SUR LES TENEURS EN ACIDES AMINÉS LIBRES DU SANG ET DU MUSCLE
}

\author{
M. PAWLAK et R. PION \\ Station d'étude des Métabolismes, \\ Centre de Recherches de Clermont-Ferrand, 63-Saint-Genès-Champanelle \\ Institut national de la Recherche agronomique
}

Dans le cadre de l'étude de la relation entre les teneurs en acides aminés libres des tissus sanguin et musculaire et la composition en acides aminés de la ration, nous avions cherché à déterminer, au moyen de régimes à base de blé convenablement supplémentés en acides aminés, l'influence d'une diminution des apports alimentaires de l'ensemble des acides aminés (PAwLAK et PIon, I968c). Nous avons, dans la présente expérience, étudié grâce à l'emploi de rations contenant des protéines de tournesol, l'influence d'une augmentation de l'ensemble de ces apports, tout en comparant les effets d'une diminution à ceux qui avaient été obtenus dans le cas du blé.

Le régime de base utilisé contenait comme seule source de protéines du tourteau de tournesol supplémenté par de la lysine, de la thréonine, de la méthionine et du tryptophane (tabl. I). Sa teneur en matières azotées $(\mathrm{N} \times 6,25 \mathrm{p}$. Ioo) de I3. $\mathrm{p}$ Ioo permet de couvrir avec une marge de sécurité les besoins des animaux, dans l'hypothèse où les acides aminés du tourteau de tournesol sont entièrement disponibles.

Différents taux azotés ont été obtenus en modifiant dans les mêmes proportions les apports de tourteau de tournesol et d'acides aminés supplémentaires (tabl. 2) : ceux-ci ont varié de 73 à I 50 p. roo de leur valeur dans le régime de base, (lots I à 5). En outre, un lot de rats (no 6) a reçu un régime à taux azoté élevé (20, I p. Ioo) supplémenté seulement en lysine, l'apport des autres acides aminés indispensables par le tourteau de tournesol était suffisant pour couvrir les besoins des animaux. Les différents régimes sont isoénergétiques (4500 $\mathrm{kcal} / \mathrm{kg} \mathrm{MS}$ ) et couvrent les besoins en minéraux et en vitamines des animaux (PAwlak et Pion, I968 a). Chacun d'eux a été consommé par un lot de 8 rats à partir du poids moyen de I ro g pendant une durée de $\mathbf{} 6$ à 18 jours. Les conditions d'élevage des rats, de prélèvements des tissus, d'extraction et d'analyse des acides aminés libres de ces tissus (Moore, Spackmann et Stein, 1958) ont été décrites précédemment (Pawlak et Pion ig68 a). 
Les gains de poids et les consommations d'aliment (tabl. 2) des animaux ingérant le régime à taux azoté le plus élevé $(20,5 \mathrm{p}$. Ioo) et le régime à $\mathrm{I} 3,6 \mathrm{p}$. Ioo de matières azotées, tous deux supplémentés en acides aminés dans les mêmes proportions, sont identiques, alors que ceux des

TABLEAU I

Composition du régime équilibré

$\grave{a}$ base de tourteau de tournesol

(en g. par kg de M. S. de régime)

\begin{tabular}{|c|c|}
\hline Tourteau de tournesol $\ldots \ldots \ldots \ldots \ldots \ldots \ldots \ldots$ & 253,6 \\
\hline 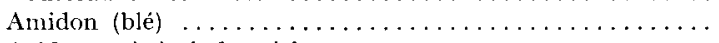 & 571,0 \\
\hline Acides aminés industriels $\ldots \ldots \ldots \ldots \ldots \ldots \ldots \ldots$ & 7,8 \\
\hline 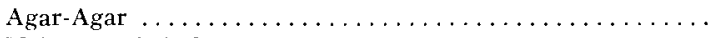 & 20 \\
\hline 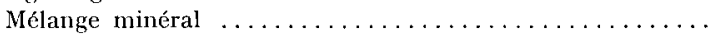 & 50 \\
\hline 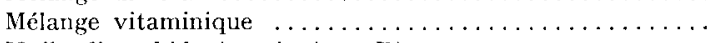 & 20 \\
\hline Huile d'arachide $(+$ vit $A$ et $D) \quad \ldots \ldots \ldots \ldots \ldots \ldots$ & 78 \\
\hline 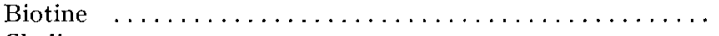 & $5 \mathrm{ml}$ \\
\hline 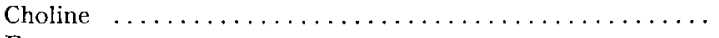 & $5 \mathrm{ml}$ \\
\hline 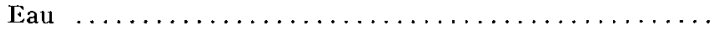 & $1100 \mathrm{ml}$ \\
\hline \multicolumn{2}{|l|}{ Supplémentation en acides aminés: } \\
\hline 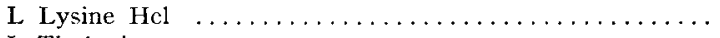 & 5,0 \\
\hline 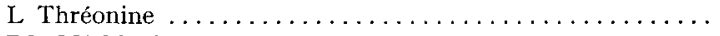 & 0,7 \\
\hline 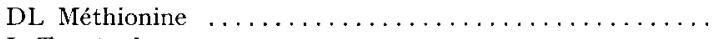 & 1,0 \\
\hline 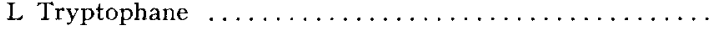 & 1,1 \\
\hline \multicolumn{2}{|l|}{ Caractéristiques: } \\
\hline Taux proétique $(\mathrm{N} \times 6, \pm 5$ p. 100$) \ldots \ldots \ldots \ldots \ldots \ldots \ldots$ & $13 \%$ \\
\hline Energie brute (Kcal/kg M. S.) $\ldots \ldots \ldots \ldots \ldots \ldots \ldots \ldots$ & 4500 \\
\hline
\end{tabular}

Biotine : solution à $40 \mathrm{mg} /$ litre

Chlorure de choline : solution à $200 \mathrm{~g} /$ litre

TABLEAU 2

Gains de poids et consommations

\begin{tabular}{c|c|c|c}
\hline \hline Régimes no & $\begin{array}{c}\text { Taux protéique } \\
\mathrm{N} \times 6,25 \%\end{array}$ & $\begin{array}{c}\text { Gain de poids } \\
\text { g/jour }\end{array}$ & $\begin{array}{c}\text { Consommation } \\
\text { g/M. S./jour }\end{array}$ \\
\hline 1 & & 4,9 & 15,9 \\
2 & 10,0 & 5,45 & 15,4 \\
3 & 12,0 & 5,3 & 14,1 \\
13,6 & 5,1 & 14,0 \\
14,0 & 5,3 & 13,8 \\
5 & 20,5 & 5,8 & 15,0 \\
6 & 20,1 & & \\
\hline
\end{tabular}

rats qui reçoivent le régime dans lequel le tournesol est supplémenté seulement en lysine leur sont légèrement supérieurs.

Une diminution de ro p. roo de la teneur en matières azotées du régime est compensée par une augmentation de $9 \mathrm{p}$. Ioo de la consommation et ne modifie pas la croissance des rats. Une 


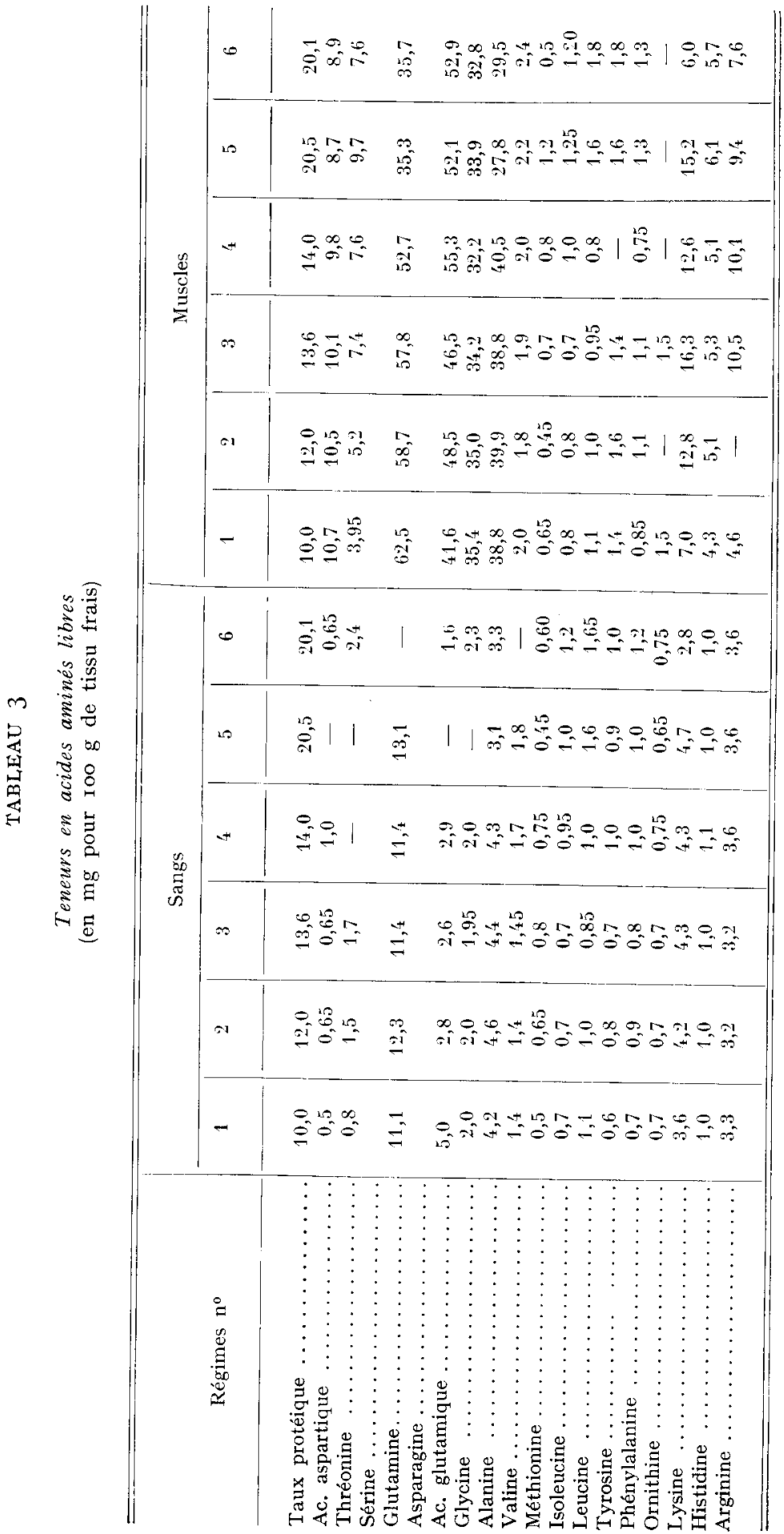


M. PAWIAK, R. PION

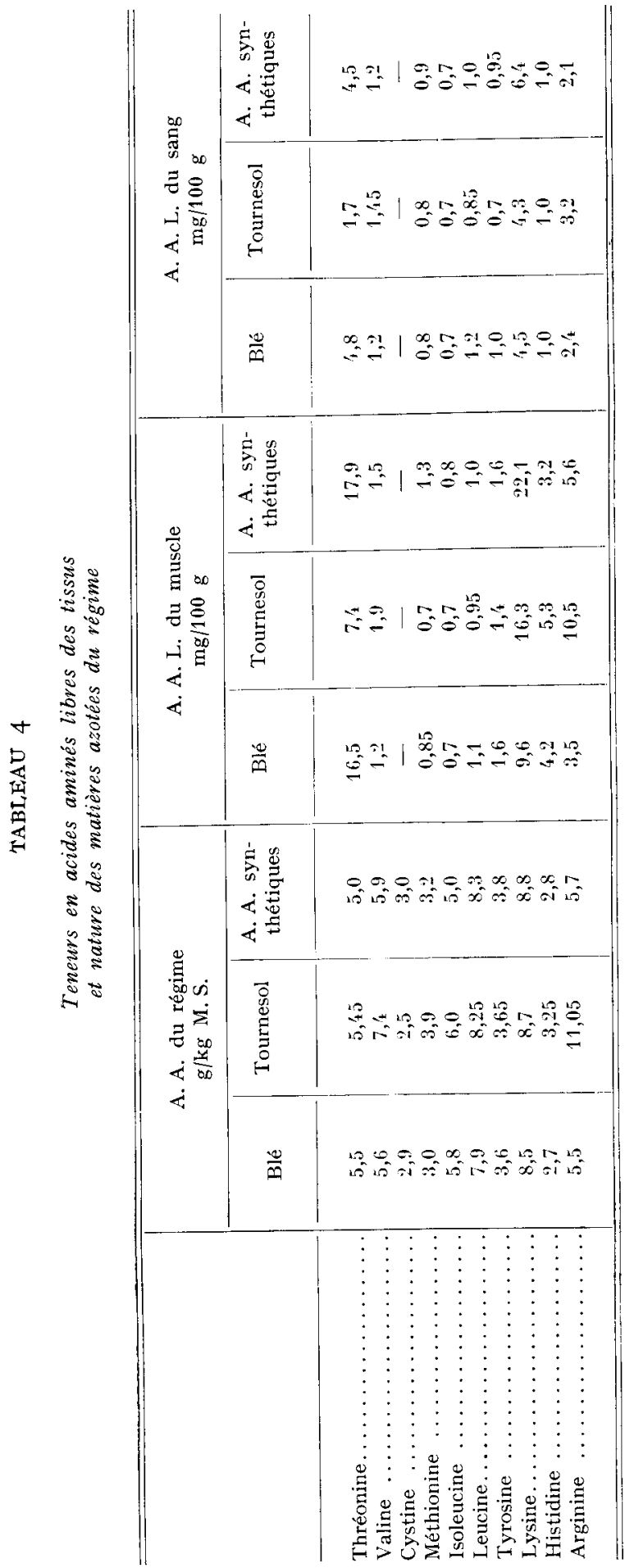


réduction plus importante (27 p. Ioo) n'entraîne, grâce à une augmentation de 13 p. Ioo de la consommation, qu'une diminution de gain de poids de $8 \mathrm{p}$. roo. Ce résultat est différent de celui que nous avions obtenu dans le cas du blé, pour une diminution du taux protéique, il est vrai plus importante.

Les teneurs en acides aminés indispensables ou semi-indispensables libres du sang et du muscle augmentent généralement avec les teneurs en matières azotées des régimes, et la valine, l'isoleucine, la leucine et la phénylalanine sont les plus affectés (tabl. 3). Toutefois, la teneur en thréonine du muscle reste sensiblement constante lorsque la teneur en matières azotées des régimes est supérieure à $\mathrm{I}_{4} \mathrm{p}$. Ioo. Ce fait peut correspondre à un équilibre enzymatique particulier des animaux ingérant des quantités excessives d'azote: Yamashita et al., (1967) et H. L. ANDERson etal., (1968) ont mis en évidence, dans ce cas, une augmentation de l'activité de la thréonine déshydratase hépatique qui permetrait la décomposition de quantités très importantes de thréonine par le foie du rat.

Une légère carence en matières azotées du régime entraîne une baisse des teneurs en lysine et thréonine libre du tissu musculaire (tabl. 3) et une carence plus importante accentue cette baisse. Le pourcentage de diminution de la lysine est plus important dans le muscle que dans le sang, alors que celui de la thréonine présente sensiblement la même amplitude dans ces deux tissus. Cette différence de comportement a déjà été mise en évidence (PAwlak et Pion, I968 $a, b$ ).

Les teneurs en lysine et en thréonine libre du sang et du muscle des animaux consommant les régimes de taux protéique élevé sont toujours plus faibles que celles qui ont été observées (PAWLAK et PION, I968 $a, b$ ) chez des animaux ingérant des rations dont les teneurs en lysine ou en thréonine sont similaires, mais dans lesquelles les autres acides aminés ne sont pas apportés en quantités supérieures aux besoins. De même, pour les faibles taux protéiques, les teneurs en lysine libre sont plus élevées que celles observées chez des animaux ingérant les mêmes quantités de cet acide aminé, sans réduction des apports alimentaires des autres acides aminés. Ces faits peuvent être dus à l'influence du taux protéique de la ration sur l'intensité de la synthèse protéique et, par suite, sur le besoin des animaux.

Chez les rats du lot 6, la diminution des teneurs en thréonine, méthionine et lysine par rapport à celles du régime 5, de taux protéique voisin, entraîne une baisse des concentrations de ces acides aminés dans le muscle. Celles-ci diminuent de $22 \mathrm{p}$. Ioo pour la thréonine et de $60 \mathrm{p}$. Ioo pour la lysine et la méthionine, alors que la diminution des apports alimentaires sont respectivement de 14, I 6 et 22 p. Ioo pour la thréonine, les acides aminés soufrés et la lysine. Les teneurs en acides aminés du tissu musculaire peuvent donc refléter la composition du régime, même lorsque le taux protéique est très supérieur à l'optimum.

Nous avons comparé (tabl. 4) dans le cas du régime de base les teneurs en acides aminés indispensables et semi-indispensables libres des tissus sanguin et musculaire à celles qui avaient été observées chez des rats consommant des rations contenant des quantités voisines de matières azotées constituées de blé supplémenté ou d'acides aminés libres, et de teneurs similaires en thréonine et en lysine.

Les faibles teneurs en thréonine libre observées dans le cas du tournesol semblent indiquer qu'une partie importante de la thréonine du tourteau utilisé n'est pas disponible pour les animaux. Toutefois, cette indisponibilité partielle n'a pas modifié le gain de poids des rats, ce qui est probablement dû à un excès par rapport au besoin de la teneur en thréonine du régime équilibré. Ce dernier a en effet une teneur en thréonine supérieure de $25 \mathrm{p}$. Ioo à la valeur du besoin, telle qu'elle peut être déduite de l'étude des concentrations en thréonine libre des tissus sanguin et musculaire (Pawlak et Pion, rg68 b).

Le fait de modifier la teneur en matières azotées du régime, sans changer la composition de ces derniers, peut avoir une influence importante sur les teneurs en acides aminés libres des tissus sanguin et musculaire et peut donc influer sur les conclusions que l'on peut tirer de leur étude : dans certaines limites, un aliment protéique donné paraîtra d'autant plus apte à satisfaire les besoins en acides aminés des animaux que le taux protéique de la ration sera plus faible ; au con- 
traire, l'utilisation de régimes riches en matières azotées tendra à exagérer des déficits ou des indisponibilités comme celles que nous avons constatées dans le cas du tourteau du tournesol étudié.

Rę̧u pour publication en janvier 1970.

\section{SUMMARY}

UTILIZATION OF AMINOACIDS FROM A SUNFLOWER MEAL BY THE GROWING RAT;
EFFECT OF DIETARY NITROGEN CONTEN'T ON BLOOD AND MUSCIE FREE-AMINOACIDS

5 lots of growing rats were given a diet with sunflower protein nitrogenous matter (table I) supplemented with lysine, methionine, threonine and tryptophan, or similar diets with higher or lower protein contents with the same aminoacid supplementation. In addition, another lot $\left(\mathrm{n}^{\circ} 6\right)$ was given a high protein diet with sunflower supplemented only with lysine. Food intake and growth rate (table 2); free aminoacid contents of the blood and muscle (table 3) were recorded. Growth rate was irrespective of variations in dietary nitrogen content, any decrease in nitrogen content being partly balanced by an increase in food intake.

The tissue contents of free lysine and threonine varied depending upon the dietary content (table 3). The free threonine contents of muscular tissue were lower in sunflower fed rats than in rats fed similar amounts of threonine in supplemented wheat of free aminoacid diets. In view of this fact, it seems that part of the sunflower cake threonine is not utilizable by the growing rat.

\section{RÉFÉRENCES BIBLIOGRAPHIQUES}

Anderson H. L., Benevenga N. J., Harper A. E., 1968. Association among food and protein intake, serine deshydratase, and plasma amino acids. Am.J. Physiol., 214, Ioo8-1or3.

Moore S., Spackman D.H., Stein W. H., I958. Chromatography of amino acids on sulfonated polystyrene resins. Analyt. Chem., 30, 1185 -1 190.

Pawlak M., Pion R., I968 a. Influence de la supplémentation des protéines de blé par des doses croissantes de lysine sur la teneur en acides aminés libres du sang et du muscle du rat en croissance. $A n n$. Biol, anim. Bioch. Biophys., 7, 517-530.

Pawlak M., Pion R., I968 b. Influence sur la supplémetıtation des protéines du blé par des doses croissantes de thréonine sur les teneurs en acides aminés libres du sang total et du muscle du rat en crois sance. C. R. Acad. Sci. Paris, série D, 266, I993-1995.

Pawlak M., Pion R., I968 c. Influence d'une diminution du taux protéique de la ration sur les teneurs en acides aminés libres des tissus sanguin et musculaire du rat en croissance. Ann. Biol. Anim. Bioch. Biophys., 7, 457-459.

Yamashita M., Eto T., Masao F., Sakurai Y., I967. Possibility of induction of threonine. Agr. Biol. Chem., 32, 374-378. 